\title{
Opportunities of the Akabane Test for Diagnosis and Monitoring of Patients with Type 2 Diabetes
}

\author{
Valery Muzhikov $^{1^{*}}$, Elena Vershinina ${ }^{2}$ and Ruslan Muzhikov ${ }^{3}$ \\ ${ }^{1}$ Med Byte Ltd, St. Petersburg, Russia \\ ${ }^{2}$ Laboratory of Information Technologies and Mathematical Simulation, Pavlov Institute of Physiology, Russia \\ ${ }^{3}$ Department of Software engineering, Med Byte Ltd, St. Peterburg, Russia
}

*Corresponding author: Valery Muzhikov, Med Byte Ltd, 195220, St. Petersburg, Gzhatskaya str. 5/3-139, Russion Federation, Russia, Tel: +7-9627228981; E-mail: mujikov_v@mail.ru

Received date: January 09, 2018; Accepted date: February 02, 2018; Published date: February 09, 2018

Copyright: ( 2018 Muzhikov V, et al. This is an open-access article distributed under the terms of the Creative Commons Attribution License, which permits unrestricted use, distribution, and reproduction in any medium, provided the original author and source are credited.

\section{Abstract}

Background: In view of its prevalence, type 2 diabetes (T2D) is a socially significant disease, which affects millions of patients. Despite the significant advances in modern medicine, there are problems with early diagnosis and effective treatment of this disease, especially at home. In this regard, it would be interesting to pay attention to the possibility of diagnosing and treating this disease from reverse the viewpoint of traditional Chinese medicine (TCM).
\end{abstract}

Methods/Design: In order to assess patterns of heat sensitivity thresholds of acupuncture channels (AC) in patients with T2D, the Akabane test was carried out on with 116 men and 190 women. For comparison, a group of healthy subjects made up of 112 men and 277 women was also used.

Results: Simple effects of paired comparisons between healthy subjects and T2D in groups of men and women, showed significant differences. The most significant differences are seen in the AC connected with the digestive system. In this case, the greatest diagnostic value is the level of asymmetry between the right and left branches of these $A C$, which varies in proportion to the level of glycaemia. Changes in the AC are stable and precede the manifestation of the functional and organic disorders inherent in this disease. This dependence allows for early T2D diagnostics and individual monitoring.

Conclusion: The combination of the Akabane test with the use of mathematical analysis in patients with T2D makes it possible to trace the entire chain of carbohydrate metabolism at an individual level and to identify regulatory violation and the compensatory mechanisms for more effective therapeutic effects.

Keywords: Akabane test; Type 2 diabetes; Hyper and hypoglycemia; Evaluation of compensatory mechanisms; Pain; Telemedicine

\section{Introduction}

In view of its prevalence, diabetes mellitus is a socially significant disease which has become akin to a pandemic, especially in recent years. According to the World Health Organization diabetes affects more than $14 \%$ of the total population of the globe, while a normal level of sugar in the blood is marked only in $76 \%$ of the population. However, despite important achievements in this field, it still has not been possible to reverse the situation in terms of its early diagnosis and effective treatment.

Main observation method for this kind of patients is real time monitoring of blood sugar level [1-5]. However, the glucose level of blood is only an end product in many-linked chain of energy metabolism in an organism, involving many organs and systems. With monitoring at this stage, high blood sugar is only a fait accompli, and there is no opportunity to trace on which level the individual regulatory failure has happened in order to provide targeted medical correction. Despite the use of various technical systems, this problem is still a leading one in reasonable treatment.
Adage goes that there is nothing new except what has been forgotten. In this regard, it would be interesting to pay attention to the possibility of diagnosing and treating this disease from the viewpoint of traditional Chinese medicine (TCM) and acupuncture, which has existed for more than 2000 years and accumulated vast experience in the diagnosis and treatment of a wide variety of diseases including type 2 diabetes [6-11]. According to TCM, effectiveness of such treatment methods depends directly evaluation of energy level in acupuncture channels (AC).

In order to quantitatively evaluate a channel's energy activity level in TCM, the so-called "sacrificial stick" test was used in ancient times in China. This test involved a burning sandal stick which was brought in time with the pulse in proximity to specific diagnostic points at the tips of finger and toe until the first sensation of pain (Figure 1). 


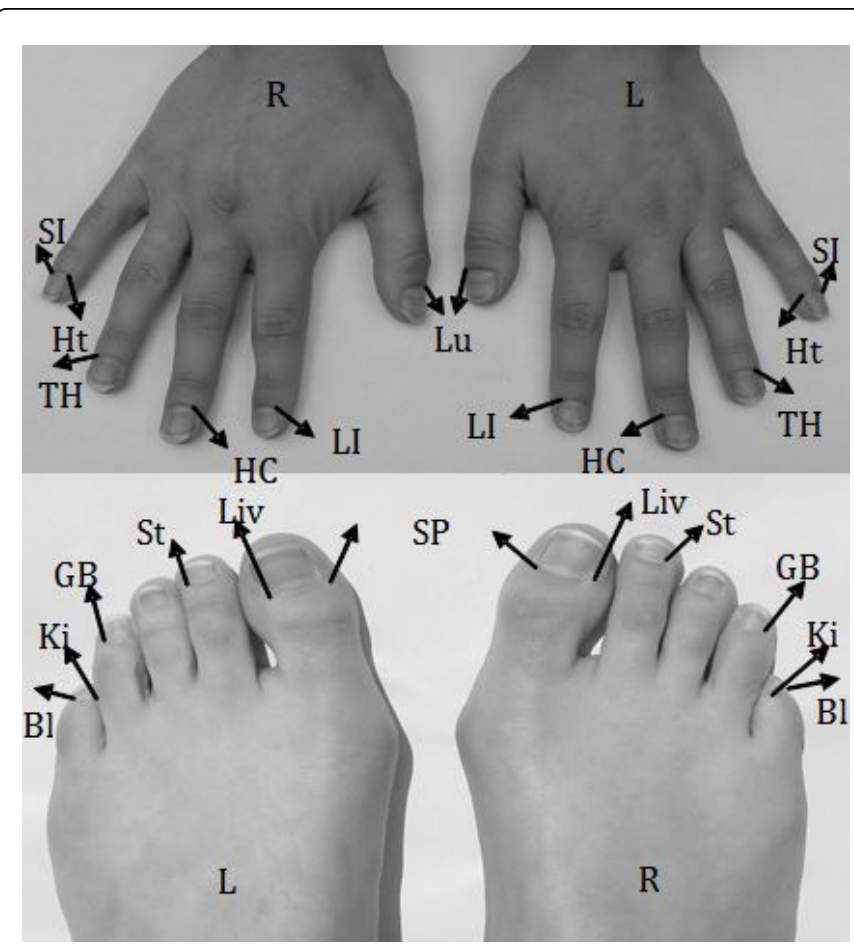

Figure 1: Topography of acupuncture points commonly used for measure of heat sensitivity in Akabane test.

At each point, calculated by the number of heat passes before was first feeling the pain. If the number of heat passes was lower than the average one for all the channels, it proved the hyperactivity of an acupuncture channel and its corresponding organ. On the other hand, when the number was higher, it represented the inactivity of a channel and its corresponding organ. This test was described by the Japanese doctor Koben Akabane in 1952 [12].

Since then, the test has carried his name, and numerous devices for the test of temperature sensitivity thresholds (TS) have been elaborated all over the world. The increased accuracy of evaluation using TS and the repeated accuracy of the method are used in connection with the fact that as humans are warm-blooded creatures, they have a highlydeveloped system for measuring temperature, down to one hundredths of a degree.

From the view of modern physiology the idea of channel energy is equivalent to notion of functional activity of organs, connected to each of these channels. So, as a result of 3-5 minute test we get digitally coded information of individual functional activity of main organs and systems of a body which participate in carbohydrate metabolism. It provides new opportunities for monitoring this kind of patients, in particular domiciliary, as this test can be performed by patients themselves.

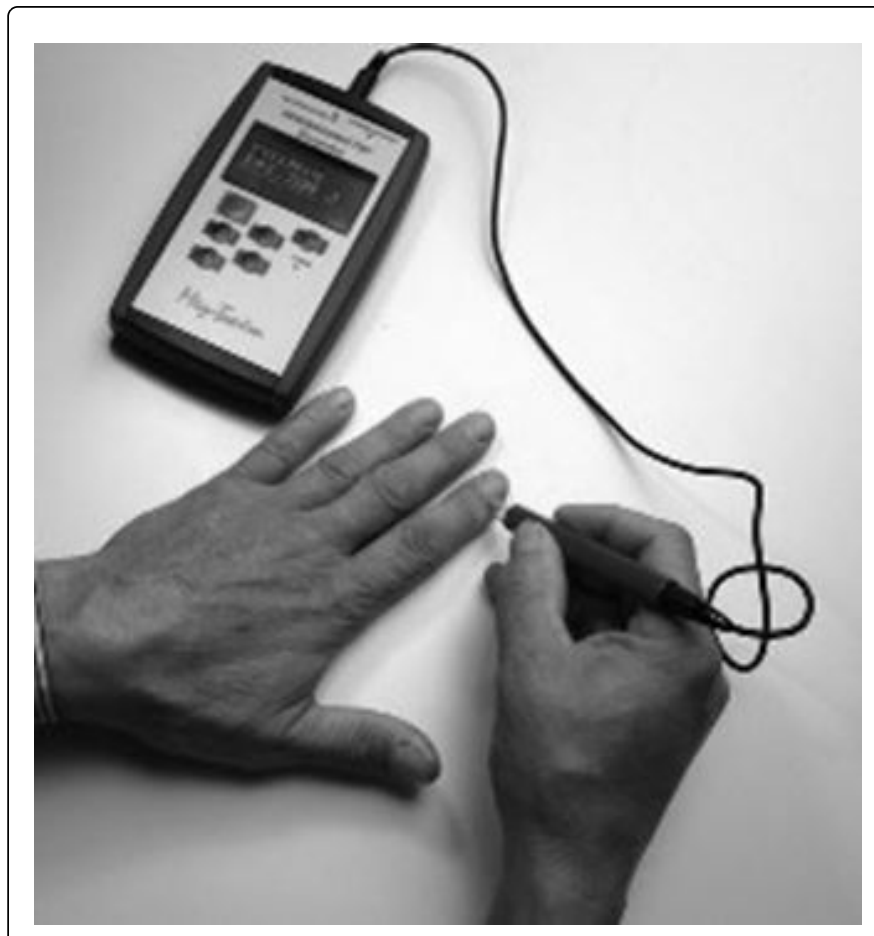

Figure 2: Individual device "Chimaster" for Akabane test and treatment.

\section{Materials and Methods}

In our study we used a special certified individual device "Chimaster", invented by Muzhikov (Figure 2) [13]. This test measures the pain TS when heat is applied to the "entrance-exit" points which are traditionally examined in acupuncture to evaluate the channels: LU11, LII1, PC9, TE1, HT9, SI1, SP1, LR1, ST45, GB44, KI1, and BL67 (Figure 1) by applying an impulse LED non-coherent IR-light onto the skin $(\mathrm{f}=1 \mathrm{~Hz}, \lambda=920 \mathrm{nM})$, with control the total energy expenditure in Joules. Each impulse radiates 0.07 Joule thermal energy.

In order to assess patterns of TS in patients with diabetes mellitus, the Akabane test was carried out on patients with T2D (116 men and 190 women). The diagnosis of diabetes mellitus was confirmed on the basis of standard examination methods in a specialized endocrinology hospital clinic environment. The average age of the patients was 56.80 \pm 11.2 years. For comparison, a group of healthy subjects of 112 men and 277 women was also used. Patients with polyneuropathy were excluded from the study. Simultaneously with the test Akabane an analysis of capillary blood from the finger was carried out on all patients using an individual glucometer for sugar levels on an empty stomach in the morning before taking medications. In statistical sampling for each patient was taken no more than two tests, which were conducted on different days. The study included patients with a sugar level of 4.2 to $18.4 \mathrm{mmol} / \mathrm{l}$.

According TCM and our study results [14,15] the following channels have different regulatory functions:

LU-lungs channel, connected with the function of lungs and tissue breathing. 
Li-large intestine channel, connected with the large intestine function and its microbe flora, it participates in the regulation of arterial pressure, biochemical blood indices.

PC-pericardium channel, connected with the cardiac muscle trophicity and its structure. In addition, it is connected to muscular activity, arterial blood pressure levels and emotions.

TE-triple heater channel, connected to the central and peripheral hemodynamic, and regulates thyroid and hypophysis hormones in the body,.

HT-heart channel, regulates the cardiac rhythm, body's physical strength

Si-small intestine channel, connected to the electrolytic balance and food digestion.

SP-spleen-pancreas channel is connected to the pancreas and immunity.

LR-liver channel is connected to liver function and central nervous system, stress levels

St-stomach channel is connected to the digestion function.

GB-channel of the gallbladder is connected to the digestion function and peripheral nervous system.

Ki- kidney channel is connected to the kidney function and the sympathoadrenal system.

BL- urinary bladder channel is connected to the urogenital system, its functions and its related hormones.

As follows from this short list, each AC can reflect various physiological and biochemical body indicators in addition to basic links with certain organs and physiological systems. Each channel has 2 branches - left (l) and right ( $\mathrm{r}$ ), and in a healthy person they are in the state of energetic balance.

All data are presented as mean \pm SEM. One-way MANOVAs followed by Bonferroni post hoc tests and testing simple effects were used to analyze the effect of gender (Males/Females) and of pathology factors (healthy people-Norm and patients with T2D) on the profiles of TS, with an evaluation of simple effects related to gender and pathology. In addition, the profiles of TS were compared using MannWhitney test. Statistical decisions were made at a significance level of $5 \%(\mathrm{p} \leq 0.05)$. Data analysis was provided using software package SPSS Inc. V 15.

\section{Results}

Figure 3 shows the TS profiles at $12 \mathrm{AC}$ level in patients with T2D in comparison with a norm. In general, a significant difference in TS profile in comparison with a norm is noted, especially for AC level, associated with the digestive and hormone systems. Almost the same values of TS are noted for AC level, associated with cardiovascular system. The minimum variation (deviation) of the values is identified there. In contrary, the maximum differences between T2D and a norm are identified in male patients at AC- SP, LR, ST and BL a level and in female patients at AC- LR and SP. According to TCM the high TS values obtained through the test reflect the "energy emptiness in the channels". Therefore, it corresponds to the hypo-function of organs and systems, associated with this channel, being proportional to the increase of their TS values.

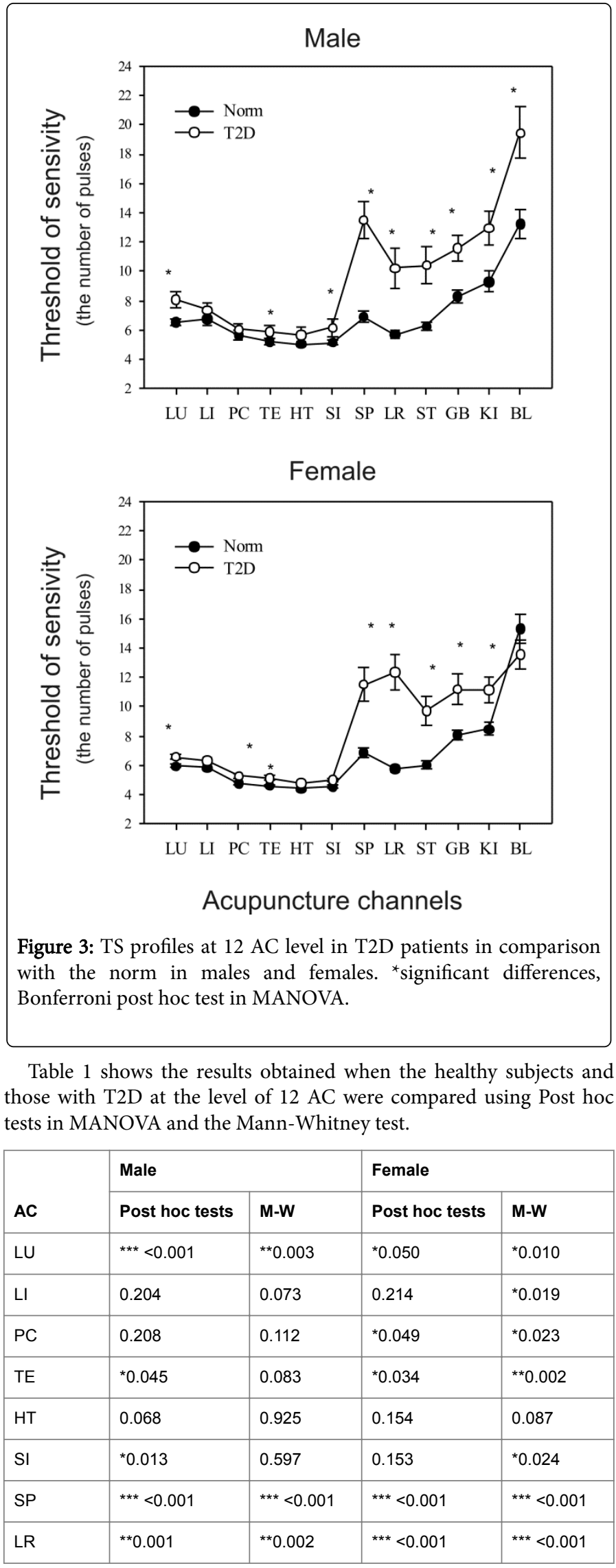


Citation: Muzhikov V, Vershinina E, Muzhikov R (2018) Opportunities of the Akabane Test for Diagnosis and Monitoring of Patients with Type 2

Page 4 of 8

\begin{tabular}{|l|l|l|l|l|}
\hline ST & ${ }^{* *} 0.001$ & ${ }^{* *} 0.004$ & ${ }^{* * *}<0.001$ & ${ }^{* * *}<0.001$ \\
\hline GB & ${ }^{* *} 0.006$ & ${ }^{* * *}<0.001$ & ${ }^{* * *}<0.001$ & 0.507 \\
\hline KI & ${ }^{* *} 0.004$ & ${ }^{* *} 0.001$ & ${ }^{* *} 0.005$ & ${ }^{* *} 0.007$ \\
\hline BL & ${ }^{* *} 0.001$ & ${ }^{*} 0.016$ & 0.222 & 0.605 \\
\hline
\end{tabular}

Note. ${ }^{*} p<0.05,{ }^{* *} p<0.01,{ }^{* * *} p<0.001,+$ tendency.

Table 1: Comparison of TS profiles of 12 AC between the Norm and T2D.

Main effects in 2X2 MANOVA are significant for both Gender, $\mathrm{F}(12.635)=2.48, \mathrm{p}=0.003, \eta^{2}=0.045$ and Diagnosis, $\mathrm{F}(12.635)=5.96$, $\mathrm{p}<0.001, \eta^{2}=0.101$. Interaction of factors Diagnosis and Gender show significance, $\mathrm{F}(12.635)=1.9, \mathrm{p}=0.028, \eta^{2}=0.035$.

Almost all channels demonstrate the significant differences in variance between a norm and T2D but the maximum differences in men marked by the as the lungs (LU) and pancreas (SP). Women are highlighted as the digestive system.

The study at the level of 24 branches of 12 AC (Figure 4) allowed to reveal another additional important difference of T2D from the norm, but they more details confirm previous addiction.

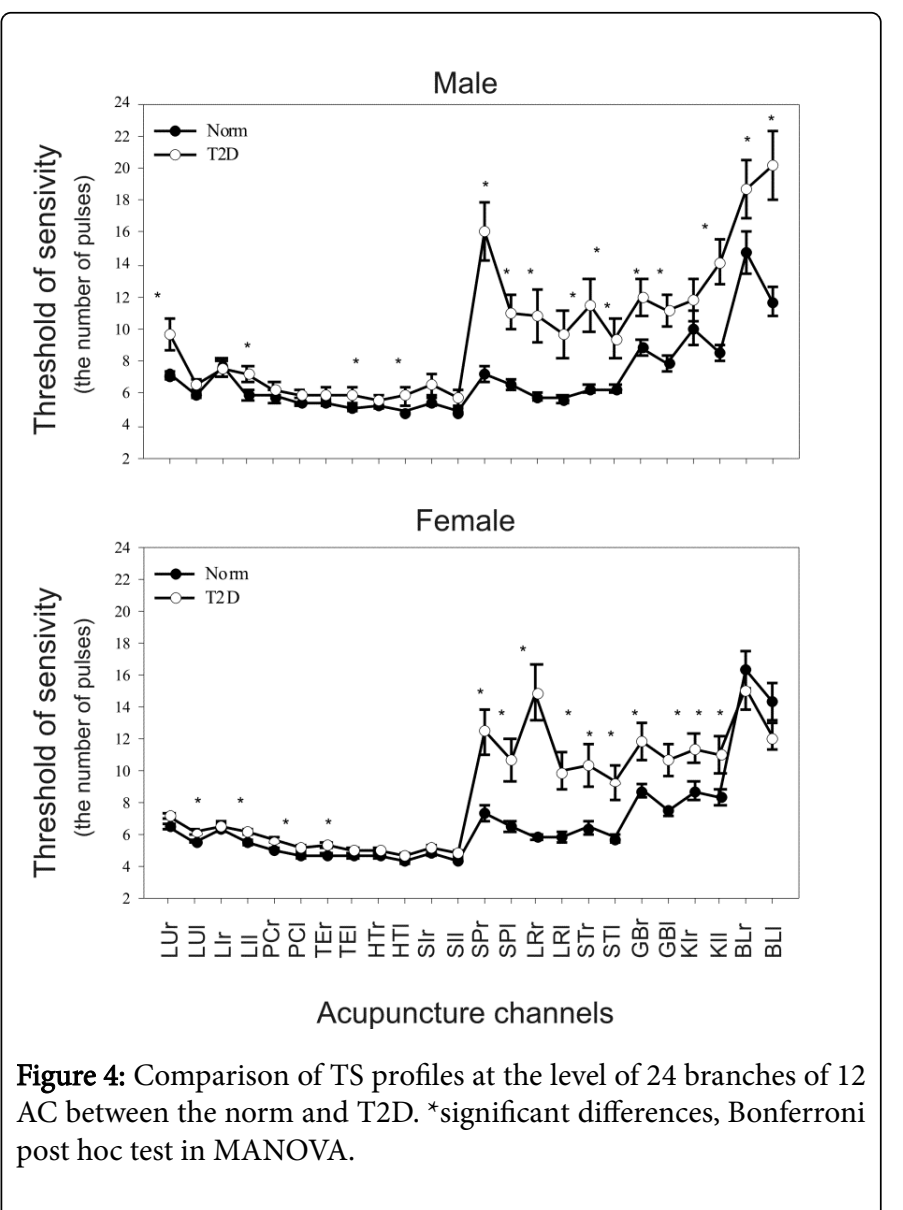

Table 2 shows the results obtained when the healthy subjects and those with T2D at the level of 24 branches of $12 \mathrm{AC}$ were compared using Post hoc tests in MANOVA and the Mann-Whitney test.

Dependent variables-factors-Gender (males/females) \& Diagnosis (Norm/T2D).

\begin{tabular}{|c|c|c|c|c|}
\hline \multirow[b]{2}{*}{ AC } & \multicolumn{2}{|l|}{ Male } & \multicolumn{2}{|l|}{ Female } \\
\hline & Post hoc tests & M-W test & Post hoc tests & M-W test \\
\hline LU r & ${ }^{* * *}<0.001$ & ${ }^{* * *} 0.001$ & 0.178 & 0.06 \\
\hline LUI & 0.082 & 0.266 & $* 0.025$ & 0.032 \\
\hline LI r & 0.912 & 0.66 & 0.683 & 0.182 \\
\hline LII & ${ }^{* *} 0.005$ & ${ }^{* *} 0.004$ & ${ }^{*} 0.041$ & 0.001 \\
\hline$P C r$ & 0.223 & 0.092 & ${ }^{*} 0.049$ & 0.026 \\
\hline PCI & 0.258 & 0.268 & 0.088 & 0.11 \\
\hline TE $r$ & 0.131 & 0.215 & **0.009 & $* * *<0.001$ \\
\hline TEI & $* 0.025$ & 0.137 & 0.16 & 0.085 \\
\hline $\mathrm{HT} r$ & 0.482 & 0.753 & 0.197 & 0.258 \\
\hline HT I & ${ }^{* *} 0.009$ & 0.714 & 0.162 & 0.052 \\
\hline SI r & 0.021 & 0.868 & 0.285 & 0.052 \\
\hline SII & 0.017 & 0.484 & 0.089 & 0.02 \\
\hline $\mathrm{SP} r$ & $* * *<0.001$ & $* * *<0.001$ & $* * *<0.001$ & $* * *<0.001$ \\
\hline SPI & ${ }^{* *} 0.002$ & 0.001 & $* * *<0.001$ & 0.013 \\
\hline LR r & ${ }^{* *} 0.007$ & 0.003 & $* * *<0.001$ & $* * *<0.001$ \\
\hline LRI & ${ }^{* *} 0.006$ & 0.004 & $* * *<0.001$ & $* * *<0.001$ \\
\hline $\mathrm{ST} r$ & ${ }^{* *} 0.001$ & 0.006 & **0.001 & 0.058 \\
\hline STI & ${ }^{*} 0.012$ & 0.088 & $* * *<0.001$ & $* * 0.001$ \\
\hline $\mathrm{GB} r$ & ${ }^{*} 0.031$ & 0.011 & 0.006 & 0.882 \\
\hline GB I & ${ }^{* *} 0.006$ & $* * *<0.001$ & $* * *<0.001$ & 0.173 \\
\hline $\mathrm{KI} \mathrm{r}$ & 0.245 & 0.055 & $*_{0}^{*} 0.018$ & ${ }^{*} 0.002$ \\
\hline $\mathrm{KII}$ & $* * *<0.001$ & ${ }^{* *} 0.002$ & ${ }^{*} 0.016$ & 0.066 \\
\hline$B L r$ & 0.079 & 0.099 & 0.457 & 0.247 \\
\hline $\mathrm{BLI}$ & $* * *<0.001$ & $* * 0.002$ & 0.155 & 0.504 \\
\hline
\end{tabular}

Table 2: Comparisons between Norm and T2D at the level of 24 branches of $12 \mathrm{AC}$.

Main effects in $2 \times 2$ MANOVA are significant for both Gender, $\mathrm{F}(24.623)=1.94, \mathrm{p}=0.005, \eta^{2}=0.07$ and Diagnosis, $\mathrm{F}(24.623)=4.3$, $\mathrm{p}<0.001, \eta^{2}=0,143$. Interaction of factors Diagnosis and Gender show significance $\mathrm{F}(24.623)=1.95, \mathrm{p}=0.005, \eta^{2}=0.07$.

According to the study results there are significant differences in variance between a norm and T2D in almost all AC, associated with a gastrointestinal tract, provided that the quantity of the significant differences in female patients is much bigger in comparison with male patients. At males and females, the greatest difference marked by the right branch of SPr. However, in males also the maximum difference 
Page 5 of 8

observed on the LUr, and females in both branches of the liver (LR) and the left branches of the stomach (STl) and GBl.

T2D profiles show the dominance TS level of the right branches of the $\mathrm{AC}$ over the left branches. As a result, Right/Left $(\mathrm{R} / \mathrm{L})$ ratio is the most effective criteria for evaluation of the body functional status. This is confirmed by the results of previous studies $[16,17]$. Figure 5 shows these profiles of the $\mathrm{R} / \mathrm{L}$ ratio in $\mathrm{T} 2 \mathrm{D}$ comparing to the norm. The diagrams show that the $\mathrm{R} / \mathrm{L}$ ratio is always higher than 1.0 even in terms of the norm. Patients T2D this ratio according to some AC exceeds the "Golden index" of asymmetry in 1.62 that does not find the explanation from the point of view of the theory of nervism where the right and left symmetrical diagnostic point must have the same parameters TS. Moreover, it is precisely those that are most associated with the formation of T2D.
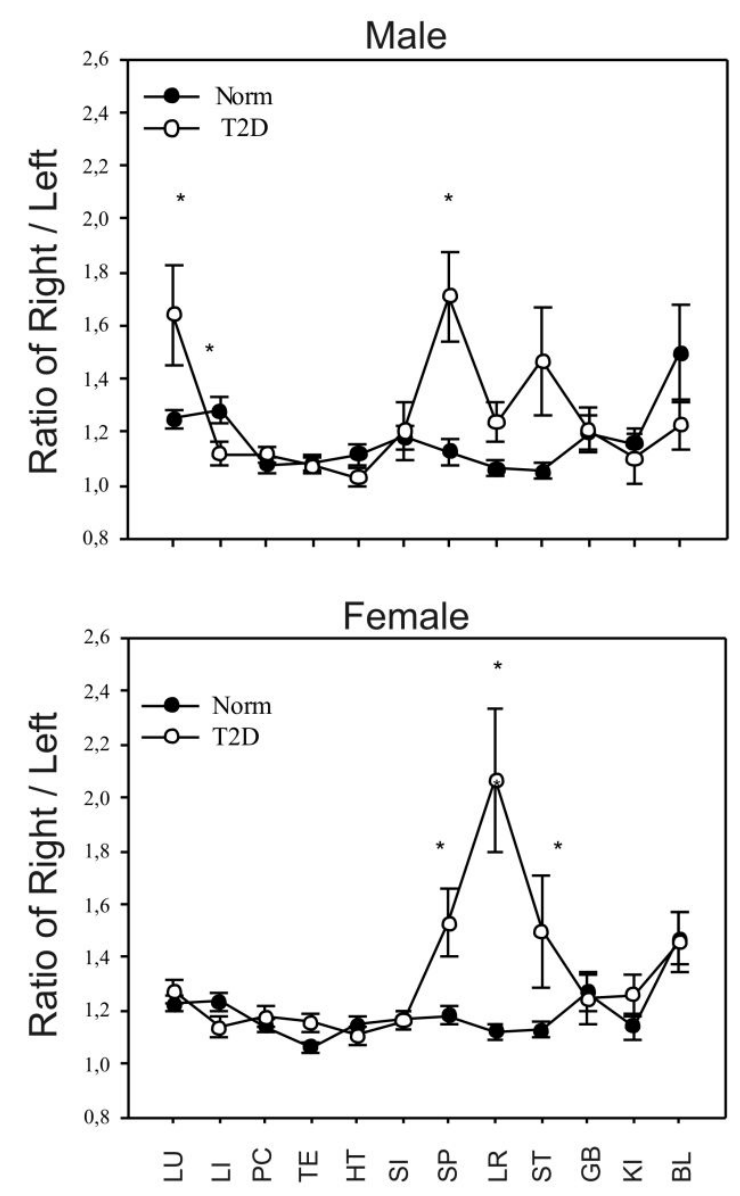

Acupuncture channels

Figure 5: Ratios of Right/Left TS of channels when comparing healthy subjects and with T2D. *significant differences, Bonferroni post hoc test in MANOVA.

The most significant differences with the norm in these TS profiles are noted in male patients in AC at LU, LI and SP points, and in female patients in AC at SP, LR and ST points. These results also evidence the more pronounces clinical damages at T2D in male patients associated with lungs, indicating the tissue hypoxia in comparison with female patients. On the other hand, in female patients the biggest differences with a maximum asymmetry on the channel of the liver are stated.

Some channels are characterized by the significant differences in variances between a norm and a diabetes condition, which are not indicated at the diagram. In particular, according to the MannWhitney test (Table 3) the differences were found in male patients at AC-LU, LI, HT, SP, KI and BL levels and in female patients at AC-LI, TE, SP, LR and ST levels. In norm ratios of $\mathrm{R} / \mathrm{L}$ is practically the same in male and female.

\begin{tabular}{|c|c|c|c|c|}
\hline \multirow[b]{2}{*}{ AC } & \multicolumn{2}{|l|}{ Male } & \multicolumn{2}{|l|}{ Female } \\
\hline & Post hoc tests & M-W & Post hoc tests & M-W \\
\hline Ratio_LU & ${ }^{* *} 0.002$ & 0.119 & 0.619 & 0.753 \\
\hline Ratio_LI & ${ }^{*} 0.015$ & ${ }^{* *} 0.006$ & 0.053 & ${ }^{*} 0.050$ \\
\hline Ratio_PC & 0.467 & 0.27 & 0.414 & 0.945 \\
\hline Ratio_TE & 0.803 & 0.542 & **0.009 & 0.076 \\
\hline Ratio_HT & 0.13 & ${ }^{*} 0.037$ & 0.357 & 0.345 \\
\hline Ratio_SI & 0.773 & 0.457 & 0.952 & 0.597 \\
\hline Ratio_SP & $* * *<0.001$ & ${ }^{* *} 0.003$ & ${ }^{* *} 0.004$ & 0.028 \\
\hline Ratio_LR & 0.493 & 0.585 & $* * *<0.001$ & 0.222 \\
\hline Ratio_ST & 0.071 & 0.417 & $*^{*} 0.028$ & ${ }^{*} 0.047$ \\
\hline Ratio_GB & 0.946 & 0.079 & 0.821 & 0.128 \\
\hline Ratio_KI & 0.618 & $* 0.013$ & 0.168 & 0.485 \\
\hline Ratio_BL & 0.171 & ${ }^{*} 0.030$ & 0.929 & 0.089 \\
\hline
\end{tabular}

Table 3: Paired comparisons between Norm and T2D at the level ratios of Right/Left TS of channels.

Main effects in $2 \times 2$ MANOVA are significant for both Gender, $\mathrm{F}(12.635)=2.0, \mathrm{p}=0.02, \quad \eta^{2}=0.037$ and Diagnosis, $\mathrm{F}(12.635)=4.86$, $\mathrm{p}<0.001, \eta^{2}=0.084$. Interaction of factors Diagnosis and Gender did not show tendency, $\mathrm{p}=0.052$. Males-Females posthocs test in the relations $\mathrm{R} / \mathrm{L}$ with T2D was detected in only 2 differences in the channels $\mathrm{LU}$ $(\mathrm{p}=0.001)$ and $\operatorname{LR}(\mathrm{p}<0.001)$.

Table 4 contains correlations of AC with fingertip blood sugar levels. Males have only 2 positive $(+)$ links to the left branch of $\mathrm{AC}$ of pancreas $(\mathrm{SPl})$ and stomach $(\mathrm{STl})$. Also there is a tendency $(\mathrm{p}=0.51)$ in connections with the right branch AC of small bowel (SIr) that is quite logical. Female have significantly more positive connections, they are all marked with (-) link vector connections to the glucose level and in most cases with right branch of LIr, PCr, TEr, Sir and KIr channels, which is quite remarkable. There is only one connection with the ACBL left branch that reflects sexual endocrine profile. Such difference between males and females can be explained by the fact that the right (Yin) branch of AC is involved in energy accumulation, while the left (Yang) - in its spending. This is responsible for general difference in right-side asymmetry of liver point values against $\mathrm{R} / \mathrm{L}$. This is the reason why the male glycemic level depends more on physical activity while the female one-on its abnormal accumulation over little wastes. 
Page 6 of 8

This conclusion is confirmed by difference between glucose link vectors: in males high liver point values with positive $(+)$ link vectors correspond with low functional activity of these systems. Consequently, this situation causes glycemia level to go up. In females, however, high right branch AC values with negative (-) vectors of glucose links tend to cause decrease in its accumulation. In TCM females are Yin, and males are Yang. It also explains general difference in gender laterality of correlation dependencies, which are also exist in evaluation of other essential body indicators [14].

\begin{tabular}{|c|c|c|c|c|}
\hline \multicolumn{5}{|c|}{ Glucose from the finger (Pearson Correlation) } \\
\hline \multirow[b]{2}{*}{ AC } & \multicolumn{2}{|l|}{ Males } & \multicolumn{2}{|l|}{ Females } \\
\hline & $r$ & Sig. (2-tailed) & $\mathbf{r}$ & Sig. (2-tailed) \\
\hline LU r & 0.093 & 0.356 & -0.079 & 0.395 \\
\hline LUI & -0.149 & 0.138 & -0.028 & 0.762 \\
\hline LI r & -0.051 & 0.616 & $-0.226\left({ }^{*}\right)$ & 0.013 \\
\hline LII & -0.027 & 0.791 & -0.152 & 0.1 \\
\hline$P C r$ & -0.09 & 0.374 & $\left.-0.263^{(* *}\right)$ & 0.004 \\
\hline PCI & -0.117 & 0.245 & -0.129 & 0.162 \\
\hline TE r & -0.065 & 0.518 & $-0.257\left(^{* \star}\right)$ & 0.005 \\
\hline TEI & -0.153 & 0.129 & -0.159 & 0.085 \\
\hline HT r & -0.129 & 0.202 & -0.175 & 0.057 \\
\hline HT I & -0.137 & 0.174 & -0.119 & 0.197 \\
\hline SI r & 0.196 & 0.051 & $-0.204\left(^{*}\right)$ & 0.026 \\
\hline SII & -0.138 & 0.17 & -0.051 & 0.581 \\
\hline SP r & -0.037 & 0.716 & 0.048 & 0.604 \\
\hline SPI & $0.200\left(^{*}\right)$ & 0.046 & -0.006 & 0.952 \\
\hline LR r & 0.058 & 0.569 & 0.14 & 0.129 \\
\hline LR I & 0.097 & 0.337 & 0.01 & 0.914 \\
\hline ST $r$ & 0.119 & 0.239 & -0.039 & 0.675 \\
\hline STI & $0.219\left(^{*}\right)$ & 0.029 & -0.026 & 0.782 \\
\hline GB r & -0.02 & 0.845 & -0.154 & 0.095 \\
\hline GBI & 0.05 & 0.622 & -0.051 & 0.58 \\
\hline $\mathrm{KI} \mathrm{r}$ & -0.043 & 0.672 & $-0.217\left(^{*}\right)$ & 0.018 \\
\hline KI I & 0.111 & 0.271 & -0.135 & 0.142 \\
\hline$B L r$ & -0.076 & 0.454 & -0.153 & 0.096 \\
\hline BLI & 0.085 & 0.403 & $-0.202\left(^{*}\right)$ & 0.028 \\
\hline
\end{tabular}

Table 4: Correlation of capillary glucose from a finger with AC.

For individual monitoring of patients with T2D optimal is the construction regression dependencies of the channels with the target parameter. Thus on one side of the scale are the channels with $(+)$ a vector of influence, and on the other with (-) vector influence. Thus it can be seen which channels contribute the most regulatory influence in the increase or decrease of the studied parameter.

Table 5 shows the regression model of correlation between AC and fructosamine level in male patients. It should be noted that fructosamine has a different chemical formula than glucose, so the channels associated with it can have a different laterality and the vector interaction. In general, this model replicates the previous correlations (SI, SP). In addition, this model includes AC- PC, this indicating the muscular load, which decrease the blood glucose level, and the AC of the small intestine, where carbohydrates are absorbed into the blood. The right branch of the AC of pancreas has the most significant influence on a fructosamine level with a positive sign $(+)$. The higher index - glycemia level will be higher.

\begin{tabular}{|l|l|l|l|l|}
\hline AC & $\mathbf{b}$ & $\mathbf{S E}$ & $\mathbf{t}$ & $\mathbf{p}$ \\
\hline constant & -0.52 & 0.26 & -1.97 & 0.06 \\
\hline LUr & 0.3 & 0.12 & 2.39 & ${ }^{*} 0.02$ \\
\hline PCI & -0.37 & 0.16 & -2.21 & ${ }^{*} 0.03$ \\
\hline SII & -0.31 & 0.22 & -1.35 & 0.18 \\
\hline SPr & 0.65 & 0.16 & 3.92 & ${ }^{* * *} 0.001$ \\
\hline
\end{tabular}

$\mathrm{R}^{2}$ (Adjusted) $=0.35$, and the standard error (SE) of the estimate $=0.21$ for $\mathrm{N}=28$ ${ }^{*} p<0.05,{ }^{* *} p<0.01,{ }^{* * *} p<0.001,+$ indicates the tendency to significance. The subscripts $r$ and $I$ indicate the right and the left branches of the AC, respectively. $A C=$ acupuncture channel; $B=$ influence coefficient.

Table 5: Regression model linking of the fructosamine with AC in males.

\begin{tabular}{|l|l|l|l|l|}
\hline AC & $\mathbf{b}$ & SE & $\mathbf{t}$ & $\mathbf{p}$ \\
\hline constant & 0.34 & 0.29 & 1.19 & 0.23 \\
\hline SIr & 0.25 & 0.13 & 1.83 & 0.07 \\
\hline TEI & -0.6 & 0.28 & -2.11 & ${ }^{*} 0.03$ \\
\hline KIr & 0.27 & 0.13 & 2.02 & ${ }^{*} 0.04$ \\
\hline HTI & 0.55 & 0.35 & 1.57 & 0.12 \\
\hline BLr & -0.04 & 0.03 & -1.24 & 0.21 \\
\hline VC & 0.42 & 0.12 & 3.4 & ${ }^{* * *} 0.001$ \\
\hline
\end{tabular}

$R^{2}$ (Adjusted) $=0.33$, and the standard error $(S E)$ of the estimate $=0.38$ for $N=57$ ${ }^{*} p<0.05,{ }^{* *} p<0.01,{ }^{* * *} p<0.001,+$ indicates the tendency to significance. The subscripts $r$ and I indicate the right and the left branches of the AC, respectively. $A C=$ acupuncture channel; $B=$ influence coefficient.

Table 6: Regression model linking of the fructosamine with $\mathrm{AC}$ in females.

In Table 6 shows the results of stepwise regression analysis for females. It is marked the same AC that in the regulation of glucose TEl, SIr, KIr, BLr. In addition this model includes channel heart $(\mathrm{HTl})$, which is involved in the regulation of physical activity. Additionally, the Model includes unpaired channel VC with the positive vector of communication which has the most significant effect $(\mathrm{p}=0.001)$ on fructosamine level. This channel according to TCM collects all Yang energy which is adequate glucose. The higher the value of VC, then the higher the level of glucose in the blood. 
Page 7 of 8

\section{Discussion}

Study of temperature sensation is the psychophysiological method. There is no its objective criterion until now, as the temperature pain threshold is subjective. Patient observed, decides himself how to evaluate his sense - either indifferent or the painful, i. e. the method is subjective by its nature.. But the thing is that our mind is essential for all regulatory processes. And if we regard these results as psychological phenomena, we get the tool of evaluation central regulation besides segmental and ganglion level. That said, with TS evaluation we get a new principle, as well as a new instrument for efficient monitoring of carbohydrate metabolism chain. On the other hand, using mathematical analysis as a truth criterion we can see direct implementation of TCM knowledge into results interpretation on the level of concepts of Yang/Yin, right/left symmetry, etc. Thereby using mathematics as an interlink, we are connecting Traditional Chinese Medicine with modern physiology.

There is a significant difference in regulatory correlation of the AC and a glycemia level in groups of males and females patients, that should be considered when performing therapeutic interventions. In females groups a significant disorder in AC liver is observed more often, also there are the significant differences in the triple heater channel (TE), which represents the thyroid status and basal metabolic rate. In male groups there was a dietary factor due to a gastric canal damage along with a tissue hypoxia (AC- LU) and small intestine and pancreas damage, which is more typical for type 1 diabetes. Figure 6 shows a diagram of communication channel SP with the pancreas, described by us previously [16-18]. From this it is clear why the growth $\mathrm{SPr}$ with the (+) vector of influence leads to the growth of fructosamine in Table 5. The higher its value TS, the lower the activity of B- cells in the pancreas. In this case the left branch canal of the pancreas reflects the activity of A-cells. Normal indicators of TS have a difference of $10-15 \%$. Inhibition of B-cells at T2D can occur during the periodic injections of insulin, which is applied in part these patients.

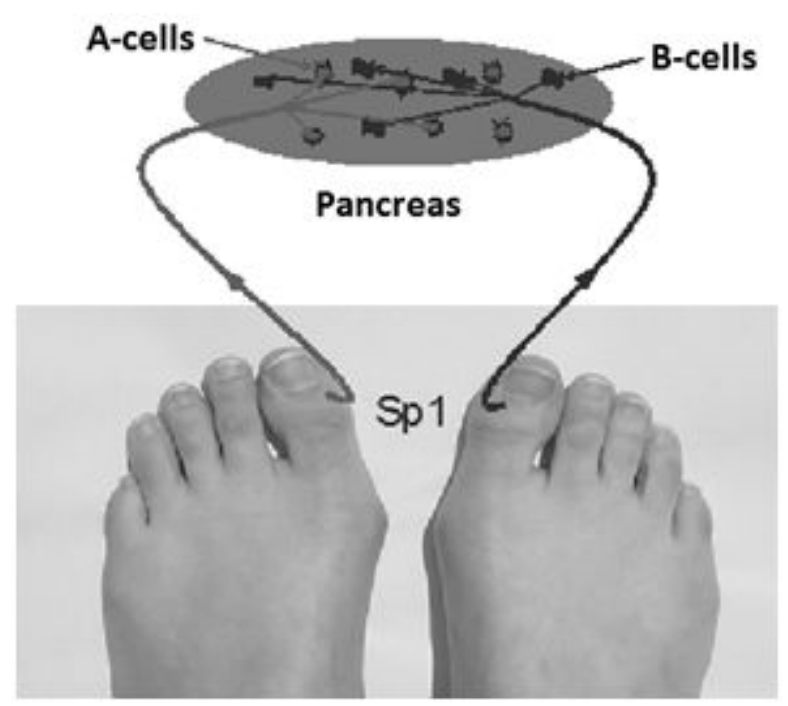

Figure 6: Linkage of points SP1 with the A- and B- cells of the pancreas.

An important difference between male and female patients in profile TS refers to AC- $\mathrm{BL}$, which reflects the status of hormone profile of the reproductive system. Thus, in male patients there is a hypofunction of reproductive hormone systemprobably related with tissue hypoxy in comparison with a norm is observed. In female patients these channels are almost identical to a normal. It is worth mentioning, that recovery of the normal sexual activity in male patients results in a decrease of glycemia.

Besides specific profile of TS those dealing with T2D should pay attention for high TS deviation along various AC in response to changes in glycemic level. It points to presence of compensatory mechanisms maintaining homeostasis of these organs and systems. If as a response to changes in glycemic level TS remain unchanged, it may be indicative of letdown of a body's reserve and compensatory capacities from these systems.

Problem of symmetry/asymmetry in biological objects is fundamental. Unlike inanimate nature, where symmetry predominates, in animate nature everything is asymmetrical, however, normally this asymmetry does not exceed "Golden ratio proportion" of 1.62. Stable higher asymmetry leads to chaos and destruction of an organism [14]. High asymmetry of values in right and left branch of the same AC usually indicates functional or organic pathology in relating organs. Such asymmetry can be effectively removed via reflexotherapy [7,9-11]. Now, influence to CV -12 point results in efficient decrease in glycemia levels at T2D [6-8]. According to our method, stimulating influence shall be performed on the side with high rate of ST, that reflect functional insufficiency. At this, simultaneously with symmetry recovery, main functions of the organ also increase $[19,20]$. Thus the main goal of such treatment is the restoration of harmony of the energy in the body, which ultimately, according to the TCM creates "healthy body and healthy mind".

The Akabene test enables to obtain an adequate information in digital form on the functional activity of different body systems and organs, which participate in forming of the carbohydrate metabolism chain. Moreover, the patient can perform the test independently by himself within 3-5 minutes only. This approach, unlike the conventional one, which needs a constant estimation of a glycemia level, provides new principles and possibilities especially for telemedicine along with wide acceptance of mathematical analysis. The best way to do it is to construct individual regression models of links between AC and blood sugar level $[14,17,19,20]$. Moreover, it is possible to construct regression models of how $\mathrm{AC}$ is linked to various medicines or their dose or time after administration. In such a manner it is possible to individually find a medicine and its best dose to neutralize sugar level increase acting by the same regression models of links to sugar $[14,16]$. This method provides new concepts for efficient and applicable monitoring. This is the first attempt to implement this idea was made, creating a conceptional bridge between the eastern and western medicines.

\section{Future directions}

In addition, using self-learning neural networks (NGO) on individual databases, it is possible to estimate the blood sugar level with an accuracy sufficient for home monitoring using for the calculations the results of the evaluation TS [21]. Changes in the level of glycemia are always late changes TS because of the buffer properties of the blood. This gives a temporary opportunity to implement a preventive correction to avoid dangerous complications. Even more significant opportunities are opened with the application of the evaluation of individual biorhythms of interested organs and physiological systems. Thus, using Cosinor analysis [22,23] when 
processing individual databases, it is possible to predict the level of glycemia for several days ahead with the detection of dangerous time periods. They are formed when, due to interference of different periods of vibration of several sugar-bound channels, a dangerous situation is formed when their total vector from the regression model to the growth and blood sugar increases sharply. In this case, there is more time for targeted correction.

In general, the future development of this technology is associated with the creation of individual devices based on the Akabane test, which have a connection to the server where the data is processed [24].

\section{Disclosure Statement}

The authors declare that they have no conflicts of interest and no financial interests related to the material of this manuscript.

\section{References}

1. Allen NA, Fain JA, Braun B, Chipkin SR (2008) Continuous glucose monitoring counseling improves physical activity behaviors of individuals with type 2 diabetes: a randomized clinical trial. Diabetes Res Clin Pract 80: 371-379.

2. Maurizi AR, Pozzilli P (2013) Do we need continuous glucose monitoring in type 2 diabetes? Diabetes Metab Res Rev.

3. Yoo H, An H, Park S, Ryu OH, Kim HY, et al. (2008) Use of a real time continuous glucose monitoring system as a motivational device for poorly controlled type 2 diabetes. Diabetes Res Clin Pract 82: 73-79.

4. Fonda SJ, Graham C, Munakata J, Powers JM, Price D, et al. (2016) The costeffectiveness of real-time continuous glucose monitoring (RT-CGM) in type 2 diabetes. J Diabetes Sci Technol 10: 898-904.

5. Vigersky R, Shrivastav M (2017) Role of continuous glucose monitoring for type 2 in diabetes management and research. J Diabetes Complications 31: 280-287.

6. Chang SL, Lin JG, Chi TC, Liu IM, Cheng JT (1999) An insulin dependent hypoglycaemia induced by electroacupuncture at the Zhongwan (CV12) acupoint in diabetic rats. Diabetologia 42: 250-255.

7. Mohanty S, Mooventhan A, Manjunath NK (2016) Effect of Needling at CV-12 (Zhongwan) on blood glucose levels in healthy volunteers: a pilot randomized placebo controlled trial. J Acupunct Meridian Stud 9: 307-310.

8. Kumar R, Mooventhan A2, Manjunath NK (2017) Immediate Effect of Needling at CV-12 (Zhongwan) Acupuncture Point on Blood Glucose Level in Patients with Type 2 Diabetes Mellitus: A Pilot Randomized Placebo-Controlled Trial. J Acupunct Meridian Stud 10: 240-244.

9. Lee YC, Li TM, Tzeng CY, Chen YI, Ho WJ, et al. (2011) Electroacupuncture at the zusanli (ST-36) acupoint induces a hypoglycemic effect by stimulating the cholinergic nerve in a rat model of streptozotocine-induced insulin-dependent diabetes mellitus. Evid Based Complement Alternat Med.

10. Li YY, Hu H, Liang CM, Wang H (2014) Effects of electroacupuncture stimulation of "Daimai" (GB 26) on body weight, blood glucose and blood lipid levels in rats with metabolism syndrome. Zhen Ci Yan Jiu 39: 202-206.

11. Cornejo-Garrido J, Becerril-Chavez F, Carlin-Vargas G, OrdonezRodriguez JM, Abrajan-Gonzalez, et al. (2014) Antihyperglycaemic effect of laser acupuncture treatment at BL20 in diabetic rats. Acupunct Med 32: 486-494.

12. Akabane K (1956) Method Oi Hinaishin. Tokyo.

13. Muzhikov VG (2010) Patent of Germany N 202010018135.6 Tag der Anmeldung 28.05.2010

14. Muzhikov V (2003) Introduction to the energoskopia of man. Gopher Publishers pp: 412 .

15. Muzhikov VG, Nozdrachev AD, Bogdanov NN (2005) Discrete Thermopuncture Test. Report 1. Reflexology 4: 23-28.

16. Muzhikov V, Vershinina E, Belenky V, Muzhikov R (2016) Significant heat sensitivity increase detected in various types of diabetes mellitus patients by Akabane test for use of management of diabetic patients. Acupunct Electrother Res 41:1-19.

17. Muzhikov V, Vershinina E, Muzhikov R (2017) System of Thermopuncture Diagnostics and Monitoring of Patients with Type 1 Diabetes. J Altern Complement Integr Med 3: 2-7.

18. Muzhikov VG (2001) Theorie en praktijk von de invloed op de BAPpunten met gemoduleerde infraroodstraling. "Huang Ti" Nederlandse vereniging voor acupunctuur 1: 22-25.

19. Muzhikov VG, Lesogor VM, Reukov AS (2000) System of Monitoring and Correction in the Rehabilitation of Patients Suffering from Diabetes Mellitus. Methodical recommendations for doctors by the Medico-Social Expert Bureau of the Ministry of Labour and Social Development of the Russian Federation CBNTI.

20. Muzhikov VG, Nozdrachev AD, Bogdanov NN (2005) Discrete Thermopuncture Test. Report 4 The Thermopuncture Monitoring of Patients with Diabetes Mellitus Type 1. Reflexology 4: 23-28.

21. Muzhikov VG (2002) German Patent DE 199-83-992 European Patent and Trademark Attorneys, N12, 2002 WO 01/45560 A1.

22. Boden G, Chen X, Urbain J (1996) Evidence for a Circadian Rhythm of Insulin Sensitivity in Patients With NIDDM Caused by Cyclic Changes in Hepatic Glucose Production. Diabetes 45:1044-1050.

23. Cugini P, Di Palma L (1994) Cosint analysis: a procedure for estimating biological rhythms as integral function by measuring the area under their best-fitting waveform profile. Biological Rhythm Research 25: 15-36.

24. Muzhikov VG (2009) Patent on useful model of Russia N 86870 $20 / 05 / 2009$. Device for reflex correction of functional disorders of the body. 